\title{
Editorial
}

\section{Thermal Spray Technology}

\author{
Shuo Yin $\left(\mathbb{D},{ }^{1}\right.$ Jan Cizek, ${ }^{2}$ Xinkun Suo $\mathbb{D},{ }^{3}$ Wenya Li $\mathbb{D},{ }^{4}$ and Hanlin Liao ${ }^{5}$ \\ ${ }^{1}$ Trinity College Dublin, The University of Dublin, Department of Mechanical and Manufacturing Engineering, \\ Parsons Building, Dublin 2, Ireland \\ ${ }^{2}$ Institute of Plasma Physics, The Czech Academy of Sciences, Za Slovankou 1782/3, 18200 Prague, Czech Republic \\ ${ }^{3}$ Key Laboratory of Marine Materials and Related Technologies, \\ Zhejiang Key Laboratory of Marine Materials and Protective Technologies, \\ Ningbo Institute of Materials Technology and Engineering, Zhejiang, China \\ ${ }^{4}$ State Key Laboratory of Solidification Processing, Shaanxi Key Laboratory of Friction Welding Technologies, \\ School of Materials Science and Engineering, Northwestern Polytechnical University, Xi'an 710072, China \\ ${ }^{5}$ LERMPS, ICB UMR 6303, CNRS, University of Bourgogne Franche-Comté, UTBM, F-90010 Belfort, France
}

Correspondence should be addressed to Shuo Yin; yins@tcd.ie

Received 19 November 2018; Accepted 4 December 2018; Published 9 January 2019

Copyright (C) 2019 Shuo Yin et al. This is an open access article distributed under the Creative Commons Attribution License, which permits unrestricted use, distribution, and reproduction in any medium, provided the original work is properly cited.

Thermal spray is a surface modification technique where solid, semimolten, or molten feedstock powders from metals to ceramics are propelled towards and deposited onto the target surface to form the coating. So far, a variety of thermal spray processes (e.g., HVOF spray, plasma spray, flame spray, wire arc spray, and cold spray) have been developed and widely applied in a broad range of industries including aerospace, automatic, energy, medical, and marine industries. The thermal sprayed coatings provide effective protection against high temperature, corrosion, erosion, oxidation, wear, chemicals, bacteria, and so on. Particularly, certain thermal spray processes can be utilized as an additive manufacturing technique to fabricate standing-free parts or restore damaged components. Given the aforementioned advantages and great potentials, investigations regarding thermal spray processes are always a focal subject and attracting great attentions from both scientific and industrial communities.

This special issue holds 1 review and 9 original research articles. Various thermal spray technologies including cold spray, HVOF spray, arc spray, and plasma spray were used to produce coatings for wear resistance, oxidation resistance, chemical resistance, thermal resistance, and structural applications.

Q. Jia and coworkers reported improved oxidationresistance properties of arc-sprayed $\mathrm{Al}$ coating onto the $\mathrm{Ti}$ substrate through modification reaction. Their study focused on the effect of heating temperature and heating time on the $\mathrm{Ti}-\mathrm{Al}$ diffusion and the consequent $\mathrm{Ti}-\mathrm{Al}$ intermetallic phase formation. The experimental result demonstrated that thick intermetallic phases including TiAl, $\mathrm{TiAl}_{2}$, and $\mathrm{TiAl}_{3}$ were formed after heating in different conditions. Due to the formation of the intermetallic layers after modification treatment, the Ti substrate with the arc-sprayed $\mathrm{Al}$ coatings on the surface had better oxidation-resistance properties in a high-temperature environment than the pure $\mathrm{Ti}$ substrate without coating protection.

S. Yin and coworkers contributed a review on nanostructured metal coatings produced with cold spray. They first provided a comprehensive literature review on the nanocrystallization phenomenon occurring in cold-sprayed coatings. Then, the focus was switched to the microstructure and properties of cold-sprayed nanocrystalline metal coatings. They also summarized the current existing studies concerning $1 \mathrm{D}, 2 \mathrm{D}$, and $3 \mathrm{D}$ nanoparticle-reinforced metal matrix composite coatings and their properties. Based on the review, future perspectives of the cold spray technology in producing metal coatings with the nanostructure were proposed at the end of their paper.

D. Fang and coworkers contributed a research paper on the application of robotics and automation in thermal spray processes. They proposed a new method to automatically generate nozzle trajectories for producing uniform coatings on complex curved surfaces. Experimental validation 
positively proved the capability and advances of this novel method.

C. De Crescenzo and coworkers proposed a revolutionary technology based on shape memory alloy (SMA) coatings deposited on-site to large-scale metallic structural elements. Investigations were carried out by depositing commercial NiTinol Ni50.8Ti (at.\%) powder onto AISI 316L stainless steel substrates using the HVOF thermal spray technology. The main concern of this paper was studying the effect of main processing parameters including spray distance, fuel-to-oxygen feed rate ratio, and coating thickness on the quality and properties of the coating in terms of hardness, adhesion, roughness, and microstructure. The results confirmed that using optimal spray parameters could significantly improve the properties of HVOF Ni-Ti coatings. The HVOF spraying technique could produce oxidefree SMA coatings without changing the chemical composition of the coating material as compared to the original powder feedstock.

L. Fang and coworkers contributed a research article on cold-sprayed $\mathrm{Al}+\mathrm{SiO}_{2}$ metal matrix composite coatings for protecting the underlying AZ31 Mg alloy substrate. They mainly studied the role of $\mathrm{SiO}_{2}$ reinforcement in the coating property improvement. The experimental result revealed that adding $\mathrm{SiO}_{2}$ particles in the metallic $\mathrm{Al}$ coatings could significantly improve the coating properties including microhardness, adhesion strength, wear resistance, and corrosion resistance. They also found that the content of $\mathrm{SiO}_{2}$ particles in the coatings had no significant effects on the coating properties. This work proved that the cold-sprayed $\mathrm{Al}+\mathrm{SiO}_{2}$ metal matrix composite coatings could facilitate the structural applications of $\mathrm{Mg}$ alloys.

H.-S. Lee and coworkers studied the corrosion-resistance properties of arc-sprayed AISI 304L stainless steel and $\mathrm{Ti}$ coatings in $\mathrm{pH} 4$ solution. They reported that the Ti coating exhibited a uniform, less porous, and adherent coating morphology compared to the AISI 304L coating. The potentiodynamic study showed that the $\mathrm{Ti}$ coating reduced the corrosion rate by more than six times compared to the AISI 304L coating after $312 \mathrm{~h}$ of exposure to sulfuric acid $\left(\mathrm{H}_{2} \mathrm{SO}_{4}\right)$ contaminated water solution due to the uniform and globular morphology of the passive film formed on the Ti coating.

G.-l. Li and coworkers reported a new method to remelt thick plasma-sprayed self-fluxing NiCrBSi coatings with the tungsten inert gas (TIG) arc technology and to improve the properties of the NiCrBSi coatings. They found that TIGremelting treatment significantly eliminated the microdefects in the coatings and improved their density. The main phases in the as-sprayed coating changed from $\gamma-\mathrm{Ni}, \mathrm{Cr}_{7} \mathrm{C}_{3}$, and $\mathrm{Cr}_{2} \mathrm{~B}$ before remelting treatment to $\gamma-\mathrm{Ni}, \mathrm{Cr}_{23} \mathrm{C}_{6}, \mathrm{CrB}$, $\mathrm{Ni}_{3} \mathrm{~B}$, and $\mathrm{Fe}_{3} \mathrm{C}$ after. The remelted coatings had improved surface roughness, hardness, and wear-resistance properties. The result clearly suggested that the TIG-remelting technique is promising as a post-treatment method to improve the coating properties.

$\mathrm{K}$. Wen and coworkers conducted a research to investigate the thermal and flow dynamics in a plasma torch using the numerical simulation method. The flow regime of a plasma jet determines the acceleration and heating behaviors of powder particles and hence influences the quality of a plasma-sprayed coating. In this study, based on a welldesigned transient CFD model, the authors studied a number of key parameters involved in a plasma torch including arc voltage, net power, thermal efficiency, and inflight particle velocity based on a standard cylindrical plasma nozzle and a cone-shaped plasma nozzle. The modelling result showed that the geometry of a plasma torch significantly affected the thermal and flow regime of a plasma jet, therefore influencing the final coating quality.

In summary, this special issue provides a detailed account of the present status of the thermal spray technology and highlights the recent developments which cover the novel and important aspects of these technologies and their applications.

\section{Conflicts of Interest}

The editors declare that there are no conflicts of interest regarding the publication of this editorial.

\section{Acknowledgments}

The editors would like to thank all authors who submitted their research to this special issue, as well as all reviewers for their valuable contribution.

\author{
Shuo Yin \\ Jan Cizek \\ Xinkun Suo \\ Wenya $\mathrm{Li}$ \\ Hanlin Liao
}




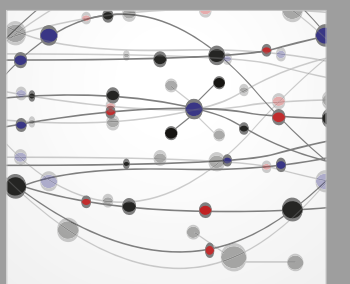

The Scientific World Journal
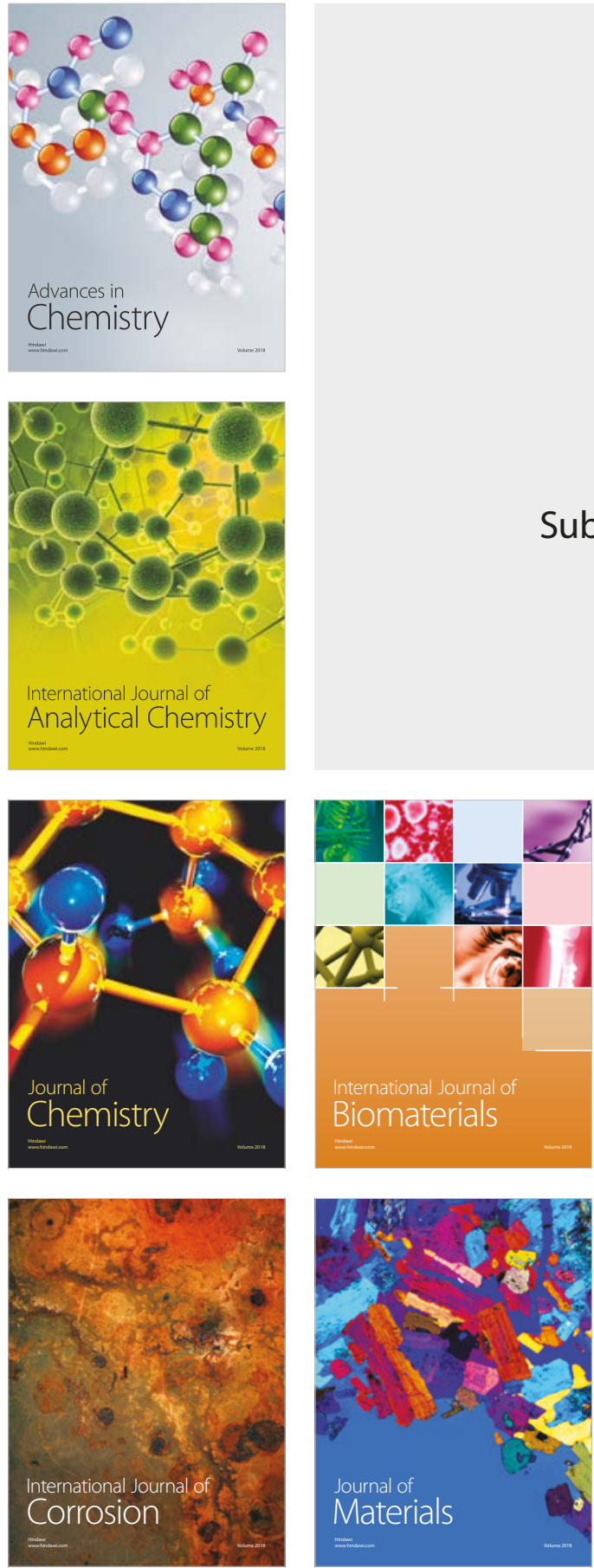

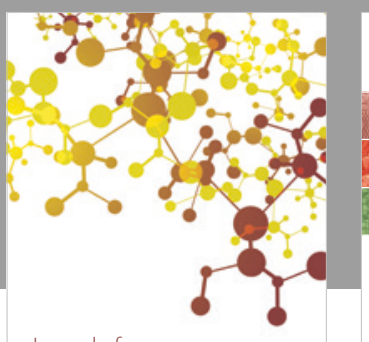

Journal of

Applied Chemistry
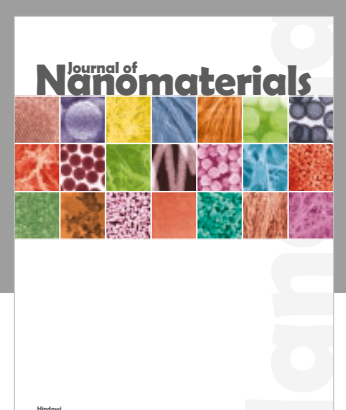

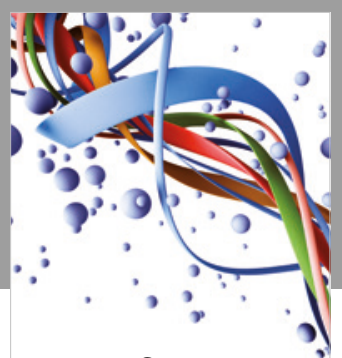

Scientifica

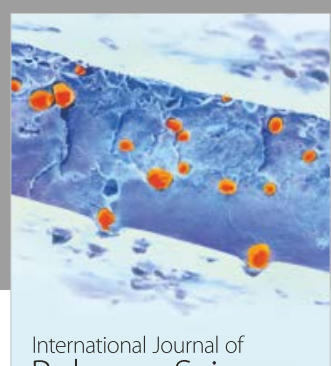

Polymer Science

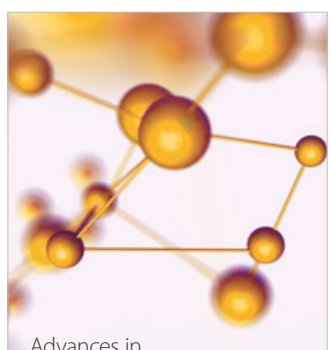

Physical Chemistry
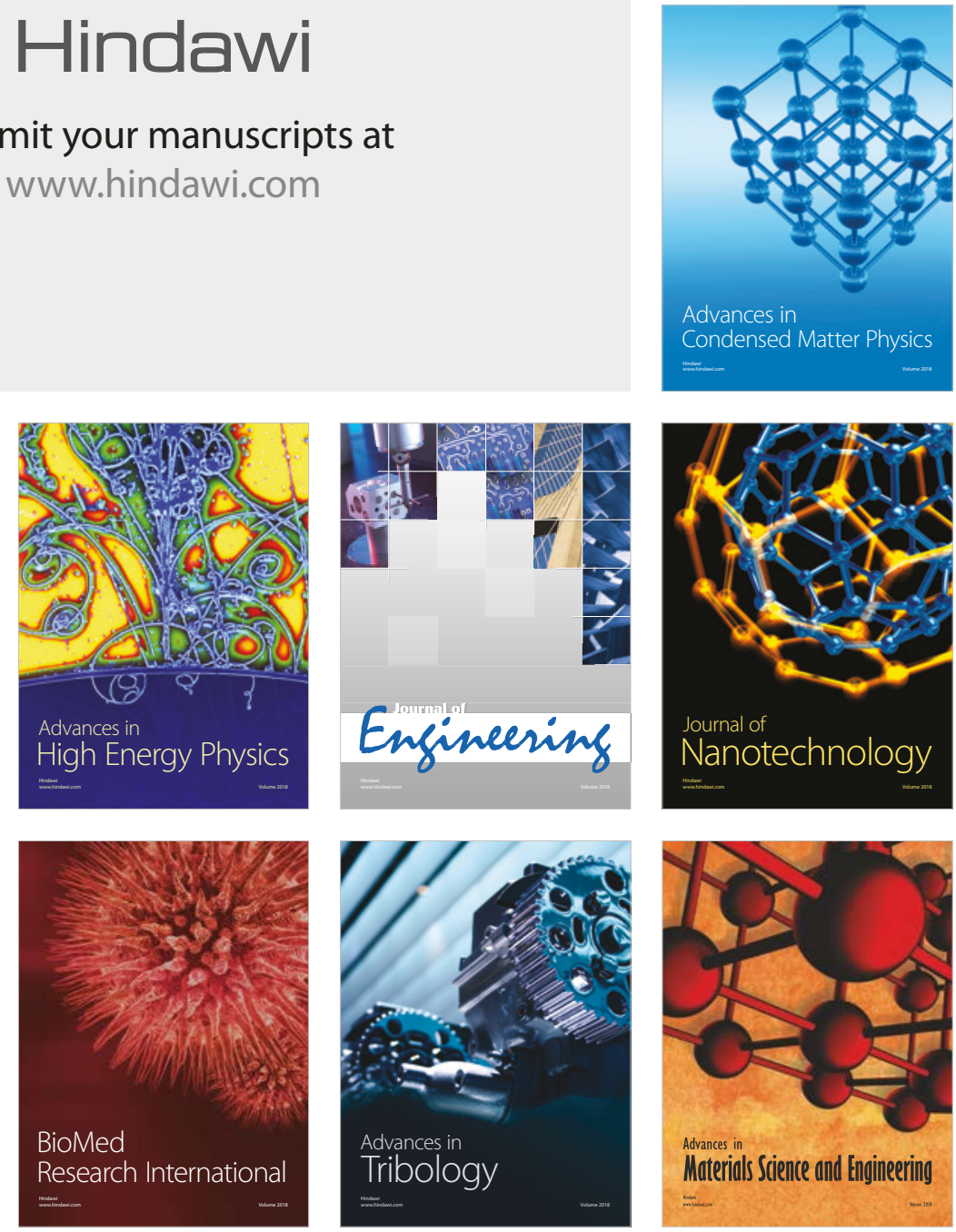